\title{
Bilingüismo y educación en la región andina: en búsqueda del aporte de la educación al mantenimiento de las lenguas indígenas
}

Inge Sichra*

\section{Resumen}

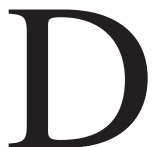

esde la perspectiva oficial, los programas de EIB en tanto proyectos de reivindicación idiomáticacultural son concebidos como una suerte de licencia o concesión a favor de los pueblos originarios, y no como parte medular e integral de sus proyectos educativos en la medida en que hagan suyo el derecho de las minorías. Aun bajo el objetivo de la educación intercultural bilingüe de liberar a los pueblos minorizados de una discriminación, las especificidades de las lenguas de los pueblos indígenas no son contempladas en la escuela. Sostenemos que la escuela, por varios y complejos motivos, no es el lugar que pueda provocar un "retorno de la lengua indígena". La tarea que los Estados hasta ahora han emprendido como planificador educativo en países con diversidad lingüística no ha contemplado la transmisión, adquisición y

\footnotetext{
* Asesora Nacional del Programa de Formación en EIB para los países andinos PROEIB Andes. Las opiniones aquí vertidas son de exclusiva responsabilidad de la autora y no comprometen de ninguna manera al Programa, a la contraparte UMSS ni a la GTZ.
} 
aprendizaje de las lenguas indígenas. Esto debido a la focalización en norma y función de las lenguas minorizadas en espacios "formales" de la sociedad hegemónica como la escuela. Se requiere el reconocimiento del ámbito no institucionalizado, público, de las comunidades y los pueblos indígenas, aceptando las distintas educaciones que en ellas existen, tanto formales como familiares; es decir, en la cotidianeidad.

Este trabajo ${ }^{1}$ es un avance de reflexión sobre algunos aspectos de planificación lingüística emprendidos a raíz del reconocimiento y legitimación de las lenguas indígenas en diversos países latinoamericanos. Después de presentar algunas nociones básicas de la planificación lingüística, visualizo el camino que esta ha ido tomando como acción estatal, poniendo en el centro la lengua y no la persona, enfatizando en la norma (escrita) y no en el uso (oral). Concluyo con reflexiones respecto a posiciones políticas y teóricas que deberían guiar y sustentar futuras acciones de planificación lingüística con enfoque crítico.

\section{Las reformas educativas de los estados y las len- guas}

Han surgido desde hace algunas décadas con mucha fuerza demandas de una educación diferente a la propiciada hasta ahora por los estados. Una educación pertinente al fortalecimiento de los pueblos indígenas es concebida de distintas maneras por las distintas organizaciones indígenas. Así las organizaciones en Colombia propugnan en sus resguardos o asentamientos indígenas una educación propia o etnoeducación, mientras que en Bolivia la demanda se concretó en una educación intercultural bilingüe a nivel nacional.

\footnotetext{
${ }^{1}$ Agradezco a Luis Enrique López por sus aportes en una revisión anterior de este trabajo.
} 
Para el movimiento indígena, la "liberación de los pueblos" es una tarea encomendada a la educación intercultural bilingüe, una herramienta en la construcción de una ciudadanía sin exclusiones, de una cultura democrática y de una igualdad que permita en la práctica el ejercicio igualitario de la ciudadanía "étnica" o la doble ciudadanía con respeto de derechos colectivos y diferencias culturales.

A inicios del siglo XXI, 17 países reconocen el derecho de las poblaciones indígenas a una educación en su propia lengua y realizan educación intercultural bilingüe en el marco de las reformas educativas en curso basadas en una política de descentralización (López 2002). A partir de la Conferencia Mundial Educación para todos en 1990 en Jomtien y siguiendo un dictado internacional, las reformas educativas abogan por un modelo educativo basado en la demanda de los padres y madres de familia y no, como hasta hace unos lustros, sustentado en la oferta elaborada desde los escritorios ministeriales con el trasfondo de la política dominante a nivel nacional. En esta perspectiva, la educación a nivel global se basa en la concepción de ser un bien individual, sin que se haya avanzado en el establecimiento de la educación como derecho colectivo. Bajo esta consigna, no obstante, la diversidad cultural y lingüística empieza a ser considerada una riqueza y recurso, no como un problema (cf. Ruiz 1984), una posibilidad de potenciamiento para que el alumno enraizado en su entorno ecológico, social, cultural y lingüístico inmediato pueda ser confrontado con otras realidades y manifestaciones y enriquecerse con este conocimiento.

\footnotetext{
${ }^{2}$ GUTIÉRREZ, Walter (2003:4), Presidente del Consejo Educativo Aimara, en Bolivia, lo expresa así: "La EIB abre la posibilidad de una educación propia; esto plantea por consecuencia una lucha de poderes. A través de la EIB como instrumento de liberación, más adelante nos permitiremos detentar el poder, con el solo afán de construir una sociedad más justa y equitativa, de respeto a los derechos que ahora solo estamos soñando".
} 
Desde su incursión en la educación formal implementada desde los estados, se distinguen básicamente dos orientaciones en la educación para pueblos indígenas: una que responde a una política educativa asimilacionista y otra de carácter pluralista (López 2002). Hasta principios de los 80 , la inclusión de la lengua indígena en los primeros años de escolarización tenía como objetivo llevar al alumno hacia la castellanización más efectiva vía desplazamiento de la propia lengua. Si bien el peso de la acción educativa se concentraba en la lengua, el trasfondo de asimilación cultural era innegable. El Instituto Lingüístico de Verano jugó un rol decisivo en esta política educativa de asimilación a través de la evangelización. Paradójicamente, también generó muchos líderes y profesionales indígenas con un alto nivel de conciencia lingüística que actualmente abogan por la conservación y el fortalecimiento no solo lingüístico sino también identitario (L. E. López, comunicación personal 13.12.03).

En la consecución de los derechos políticos, culturales y sociales de los pueblos indígenas y apuntando a una demanda de reconocimiento colectivo en la educación, se desarrolla la educación bilingüe intercultural (o educación intercultural bilingüe). Se busca enriquecer al alumno con el desarrollo de su lengua y el aprendizaje del castellano como vehículo de comunicación con la sociedad hegemónica. Se percibe la característica "aditiva" en lo lingüístico y el esfuerzo de fortalecimiento de un pluralismo cultural. De esa manera, se busca superar la condición sociolingüística por la cual únicamente la lengua dominante y de prestigio sea utilizada en todos los contextos y ámbitos y constituya un idioma de uso formal mientras que la lengua oprimida y dominada quede relegada al plano informal y doméstico.

Al cabo de dos décadas de aplicación de educación intercultural bilingüe, los resultados más notorios tienen que ver con la retención y promoción escolar (López, 1995). El uso 
de la lengua indígena en el aula y la introducción en el currículo de elementos de la cultura local generan una mayor motivación entre los niños, en general. La contribución mayor de la educación intercultural bilingüe se refiere al desarrollo de la autoestima de los niños indígenas y a su bienestar socioafectivo, base para la percepción positiva de la identidad cultural y los procesos cognitivos (íbid).

Nos interesa, sin embargo, ir más allá del éxito en el aula (Hornberger 1989 habla de éxito en el aula y fracaso en la política para el caso de la EIB en Puno en los años 80) y preguntar sobre el efecto de la EIB en las lenguas indígenas. No tenemos aun los elementos para saber si la EIB influyó de manera positiva o negativa en las lenguas indígenas, su vitalidad y su fortalecimiento en ámbitos y espacios propios. Lo que podemos hacer ahora es reflexionar críticamente sobre la intervención que supuso la EIB en las lenguas minorizadas. Sabemos, por ejemplo, que su introducción al aula ha sido a través de lo que la lengua hegemónica ostenta para su prestigio: la escrituralidad y su clásico portador, el libro. Investigaciones realizadas en escuelas bilingües como las de Hornberger (1989) y López y Jung (1989) en Puno, Francis y Hamel (1992) en México apuntan a un uso más elaborado de la lengua indígena a nivel oral en aula y al desarrollo de la complejidad estructural a nivel escrito, tanto en la primera lengua como también en castellano.

Hay sin duda toda una estrategia de política lingüística detrás de esta opción que quiere elevar la lengua indígena al desarrollo y la modernidad de la lengua oficial y de uso general. Esto se lograría en base al factor prestigio de la escritura.

\section{Política y planificación lingüística}

Una política lingüística surge en contextos donde hay un conflicto social o lingüístico latente o expreso. Este con- 
flicto generalmente tiene que ver con la búsqueda de expansión o establecimiento de espacios de poder a través de la lengua. Las lenguas dominantes, una vez consolidado su poder de prestigio, prácticamente no necesitan una política lingüística de desarrollo idiomático, a lo más, esta les sirve como mecanismo de conservación y defensa de lo adquirido; necesitan trabajar una política lingüística de "ofensiva" cuando están o se sienten amenazadas por otras lenguas que les disputan su legitimidad (como lo ejemplifica el francés actualmente respecto al inglés). La política lingüística de las lenguas minorizadas, en general y de las lenguas indígenas, en especial, ha estado guiada por el objetivo de escrituralización de dichas lenguas. Esto ha significado más que nada el desarrollo de una cultura escritural que permita a las lenguas indígenas compararse e igualarse con las demás lenguas de prestigio con fines pedagógicos.

Para López (1988: 152), la política lingüística es la determinación de los principios, metas, objetivos y estrategias para el tratamiento y uso de las lenguas habladas en una sociedad determinada. La política lingüística, por lo general, está en íntima relación con la política educativa de un país determinado.

López pone el énfasis de la política lingüística en el sentido de policy al tiempo que vincula la política lingüística con la política educativa. El concepto está relacionado con la noción de planificación lingüística como la parte operativa de aplicación de la política, a tal punto que frecuentemente se los considera sinónimos (Cooper 1997: 41). No obstante, ejemplos de política lingüística en la región permiten establecer la importancia de mantener separadas estas nociones: condiciones sociopolíticas, procesos de conformación étnica, movimientos populares (nivel de los hablantes) influyen de forma decisiva en el trabajo más técnico de la planificación lingüística tanto en su desarrollo 
como en su repercusión e impacto. Así se podrá estudiar también los efectos que medidas técnicas a nivel de lengua tienen sobre los hablantes.

Por planificación lingüística, en términos específicos, se entiende el "Proceso mediante el cual se establecen las fases de implementación de una política lingüística. Comprende también la determinación de las actividades comprendidas en cada fase" (López 1988: 152).

Haugen concibió en 1959 la planificación lingüística como el conjunto de actividades consistente en la preparación de una ortografía, una gramática y un diccionario para orientar a escritores y hablantes en una comunidad de hablantes heterogénea. Como se verá más adelante, esta concepción parece tener plena actualidad en el contexto latinoamericano. Nuevas comprensiones acerca de la complejidad de la noción de planificación lingüística no tienen suficiente efecto en tanto concreción, como por ejemplo "la planificación lingüística comprende los esfuerzos deliberados por influir en el comportamiento de otras personas respecto de la adquisición, la estructura o la asignación funcional de sus códigos lingüísticos" (Cooper 1997: 60).

Como se ve, en términos generales se habla de planificación lingüística para referirse a las acciones concretas que se piensan desarrollar en el contexto de realidades plurilingües o pluridialectales. La políticas necesitan ser operativizadas en un proceso de planificación lingüística. $Y$ esta se da en dos niveles (Kloss 1969): en el del estatus de la lengua y en el del corpus de la lengua.

\section{Planificación de estatus y de corpus}

La planificación del uso y función de la lengua (planificación de estatus) es tarea de las agencias gubernamentales y ministerios que deciden, por ejemplo, cuál va a ser la lengua oficial de una nación, qué lengua deberá usarse 
para legislar, en los juzgados, para la educación, etc.; se trata de decisiones políticas. El abrir la escuela a las lenguas indígenas ha sido, en prácticamente todas las reformas, el camino para ocupar un espacio formal educativo que implique un reconocimiento societal de las lenguas hasta entonces excluidas del quehacer público institucional.

En este contexto, no podemos dejar de mencionar la importancia que cobró el término diglosia "una diferenciación funcional entre dos lenguas, acompañada por una diferencia de prestigio, factor aparentemente principal en el uso que hoy día se hace del término." (Luykx 1998: 196). En algunos países, ha ganado muchos adeptos este término, estableciéndose hasta en el lenguaje cotidiano de maestros que diglosia refiere a una lengua dominante que comparte un determinado espacio geográfico con otra lengua subordinada.

El cometido de uso de lenguas indígenas en la educación solamente fue logrado después de establecer una norma escrita, elaborar un lenguaje pedagógico, vocabulario y estilos apropiados para producir materiales en las lenguas indígenas. Por lo general, las agencias que se encargan de este trabajo (planificación de corpus) son del ámbito académico, instituciones educativas estatales, a veces organizaciones indígenas. Sucede con frecuencia que estas agencias no gozan de la representación o legitimidad de la comunidad lingüística, lo cual hace difícil su labor en tanto difusión y aceptación de las normas que establece entre los hablantes. Esto debido también a la diversidad dialectal inherente a lenguas dominadas que dificulta la percepción de una unidad en la comunidad lingüística y acrecienta la notoriedad sociopolítica de la comunidad de habla. Por otro lado, diferencias de clase (expresadas por ejemplo en la existencia de burguesías ilustradas y su rol tradicionalmente fuerte en asuntos de planificación lingüística) en una comunidad lingüística tienen repercusiones aún en contextos indígenas (L. E. López comunicación personal 13.12.03). 
Cooper (1997) añade, a los dos tipos de planificación señalados, la planificación de la adquisición de la lengua. Fundamenta esta opción con el argumento de que la difusión de la lengua y sus usos implica el aumento de los usuarios. A su vez, "los cambios de función y de forma promovidos por la planificación formal y funcional afectan al número de usuarios de una lengua y a su vez, son afectos por este" (Cooper 1997: 46). En teoría, por lo menos, "la función, la forma y la adquisición de una lengua son aspectos interrelacionados, los planificadores de uno de esos aspectos deberían tener en cuenta los demás" (íbid).

En cuanto a las críticas que se formulan contra el concepto de planificación lingüística aquí expuesto, se distinguen dos, que resultan de la cercanía con la planificación educativa (cf Garcés 2005): primero, que se constriñe a la lengua escrita, oficial y formal y, segundo, que es una actividad institucional que se refiere a espacios formales, dirigida a los usos oficiales y públicos, no al uso casual y cotidiano (Christian 1992:233). Aunque algunos autores hablan de planificación dirigida a las lenguas minoritarias, lo hacen para referirse a la normalización que implica una codificación, por lo tanto, la escritura. No alcanzan a las características principales en la que se desenvuelven la mayoría de nuestras lenguas minoritarias: la oralidad y el uso cotidiano, sin supeditaciones a las orientaciones de una institución, en el sentido formal y oficial de las lenguas dominantes. En segundo lugar, es preciso mencionar los varios sentidos que la noción de planificación ha recibido en la sociolingüística desde la vertiente de los estudios de la comunicación, etnometodología, teoría de la inteligencia artificial, etc., donde se distinguen niveles individuales, familiares, comunitarios de planificación de uso de lengua. Desde la perspectiva multidisciplinaria, las elecciones que realizan los hablantes son planificadas y no son producto de casualidades ni de determinismos, menos de "aquellos factores 
sociopsicológicos naturales que regulan la situación" (Christian op.cit.233-234). También se critica la falta de flexibilidad para atender la diversidad de situaciones lingüísticas que afectan a las lenguas minoritarias. Otro aspecto casi olvidado por la planificación lingüística es que, en última instancia, se trata de aumentar el número de usuarios para que una lengua se expanda, más allá de su forma y función. Finalmente, el punto débil que mientras tanto ha recibido mayor atención es que la tarea no puede solamente ser competencia de un planificador, sino de los propios afectados.

\section{La oposición norma y uso}

Como nos indica el sentido común, la cuestión de política o planificación lingüística pasa por un problema político, de discriminación, de desigualdad social. Zimmermann (1999: 11) nos lo recuerda:

Sostenemos la tesis de que en la política lingüística no es la lengua misma el objeto de la política, sino que se trata de un medio para alcanzar otros objetivos. La política lingüística es entonces instrumento de otro objetivo político (no sabemos de ningún caso en el que se realice política lingüística por la lengua misma).

Sin embargo, dado el énfasis lingüístico en la planificación de lenguas, no resulta ser siempre evidente "que en la planificación lingüística es más importante el fenómeno sociológico que el lingüístico" (Fishman 1995: 199).

En la terminología sociolingüística se utiliza también un par de conceptos (Coserio 1982 [1962] en referencia a la política lingüística útiles para nuestra reflexión: norma y uso. Quizás estos conceptos sirvan mejor para entender que la expansión de uso antecede a la norma, especialmente en procesos de dominación lingüística que son refle- 
jo de la situación de opresión social. Recurro a Garcés (2005) en la breve discusión al respecto:

Las normas lingüísticas son "empresas sociales, estructuradas y explícitas (discursos, reglas, evaluaciones, sanciones), que emanan de subgrupos de locutores y que ejercen una acción clasificatoria y jerarquizante con respecto al funcionamiento del lenguaje" (Bronckart en Idiazábal 1998: 216). Bronckart distingue tres tipos de normas: de poder, de elite y de identidad. Las normas de poder son las que vienen sancionadas por instituciones como la academia o la escuela; son procesos normativos "fuertes", basados en gramáticas prescriptivas y con influencia, sobre todo, en los usos escritos de la lengua. Las normas de elite vienen elaboradas por los grupos sociales de elite (literatos o políticos); no son instituciones propiamente normativas pero adyacentemente emiten normas de uso. Finalmente, las normas de identidad hacen referencia a las que surgen de iniciativas de grupos sociales más o menos delimitados (feministas, adolescentes) que quieren marcar con el lenguaje su identidad; aunque a veces discrepan de las normas generales de uso, también marcan pautas modélicas (íbid).

Tal como lo comenta Garcés (íbid), a quien sigo en lo referente a Idiazábal y Bronckart, aun reconociendo que el uso va siempre por delante de la norma, encontramos que la normativa está siempre ligada al desarrollo y modernidad de una lengua. Se pregunta Idiazábal (1998:217) "¿Por qué se considera imprescindible que una lengua tenga un código descrito en una gramática, un léxico acumulado en un diccionario y una selección de textos escritos por autores de prestigio si nadie recurre a estas instancias para el funcionamiento verbal habitual?" Las gramáticas, los diccionarios y las antologías de textos selectos solo sirven como modelos académicos y dentro de la escuela tradicional. Se recurre a ellos cuando hay que enfrentarse a 
cierta escritura que necesite mostrar erudición y que esté en consonancia con lo planteado desde diversas instancias educativas. Así, se le atribuye un tremendo peso a la normativa única cuando esta apenas contempla rasgos transferibles a usos más dinámicos y modernos de la lengua. $Y$ a pesar de ello, políticos, educadores, padres e instituciones le dan una importancia mayúscula. En estos espacios, "su aprendizaje y transmisión es una de las tareas más importantes, de las más sancionadas, entre las encomendadas a la escuela" (íbid).

Para el caso específico de las lenguas indígenas, la apuesta a lo normativo viene de la mano con lo que Zimmermann (1995:84) llama "el problema educativo de moverse entre la variedad hablada y la escrita de una lengua". Y se llega al extremo de contraponer el dilema inherente a la acción educativa vía escritura a un escenario dramáticamente fatalista: "Pero más grave que este problema sería la muerte de la lengua" (íbid). Sin embargo, es difícil encontrar sustento para esta convicción, tanto en la historia de desarrollo y desaparición de lenguas como en argumentos de orden teórico. El mismo autor (Op. cit.:83) no encubre la debilidad del fundamento para priorizar la forma escrita (normatividad):

La creación de una escritura es una de las tareas primordiales de defensa activa de una lengua. Por el hecho de la variación interna de cada lengua histórica, nos encontraremos en muchos casos frente al problema de la normalización de la lengua respectiva. Hasta el momento, no conozco otra solución que la normalización de la lengua escrita y el sistema ortográfico. Hasta la presentación de una solución menos coercitiva, tenemos que aplicar este método.

No se concibe, al parecer, la posibilidad de recurrir a otro tipo de normas que las de poder ser mencionadas por 
Bronckart, aquellas que vienen sancionadas por la escritura. Cabría aquí preguntarse si estas normas de poder no están nuevamente establecidas por la sociedad hegemónica, por una academia de la lengua (indígena) con miembros no indígenas. Las normas de elite y sobre todo las normas de identidad que marcan pautas modélicas no son consideradas como referentes. Probablemente nos hayamos sentido muy cómodos en nuestra perspectiva lingüística y sociolingüística marcada por el hecho de provenir de contextos específicos de lenguas con tradición escrita:

Todas las lenguas que tienen alfabeto padecieron tarde o temprano el mismo problema. Esta estandarización (eliminación de la variación) constituye en el mismo momento de su introducción un problema de identidad lingüística entre los hablantes $y$, con ello, un problema de aceptación. Pero más grave que este problema sería la permanencia de la variación, con ella la reducción del ámbito comunicativo y un debilitamiento de lo que de todos modos ya está debilitado. Es verdad, las lenguas europeas al inicio de su paso a la escrituralización escrita (sic) lograron cumplir esta función durante bastante tiempo sin normativización...pero al fin y al cabo todas adoptaron esta ingerencia. (Zimmermann 2003:94).

¡No deja de sorprender que a este nivel de la discusión se siga creyendo en la ya enterrada transferencia tecnológica! La teoría crítica ha permeado también a la sociolingüística y le ha permitido superar el positivismo con el cual se dedicaba a las "desigualdades" de las lenguas. Esta posición, como lo admite el propio Fishman (1994: 94) citado en Ricento (2000:20) "has tended to reproduce sociocultural and econotechnical inequialities", de manera que "language planning is often con- 
nected to the processes of Westernization and modernization"3.

\section{La prioridad del uso en las lenguas indígenas}

Aún no conocemos el funcionamiento de las lenguas indígenas en los distintos ámbitos sociales en los que lucha por abrirse paso. Aún nos falta, en casi todas las lenguas indígenas, una etnografía de la comunicación sólida y detallada. Quizás se deba precisamente al trabajo de académicos y al esfuerzo por superar el fenómeno de la diglosia ocupando espacios formales reconocidos por la sociedad hegemónica donde se producirían nuevos estilos, nuevos vocabularios, nuevas ideas, que se ha dejado de estudiar lo cotidiano. Se puede deber también al lastre estructuralista entre los lingüistas descriptivos, a la falta de sociolingüistas y de etnógrafos de la comunicación. Quizás sea tiempo de acercarnos "académicamente", "políticamente" (en tanto planificación lingüística) a la real dimensión de lo cotidiano en tanto espacio de generación de conocimientos y creatividades. Como diría Heller (1982), en lo cotidiano se cristalizan el "pensamiento y la acción". El tema de lo cotidiano nos interpela nuevamente, esta vez también desde la perspectiva de política lingüística, más allá del interés antropológico.

Sostenemos que la negligencia en el estudio y la apreciación de lo cotidiano también nos ha impedido, a los estudiosos, descubrir el tejido de espacios formales indígenas que los hablantes aún reservan a sus lenguas, complejidad velada por la asumpción de un constructo de política lingüística como "diglosia" que, si bien sirvió para propiciar acciones estatales, no permitió ver la distribución de usos

\footnotetext{
1 "Ha ido reproduciendo inequidades socioculturales y técnico-económicas" de manera que "la planificación lingüística ha estado a menudo conectada a los procesos de occidentalización y modernización”. (Traducción de la autora).
} 
de lenguas más allá de las categorías "funciones altas" y "funciones bajas" que la sociedad hegemónica estableció para sus fines de legitimación de asimilación. Así, mientras el esfuerzo de deconstruir la diglosia a través de la "conquista" de la escuela como ámbito de uso de lenguas indígenas implicaba ingentes recursos y energía de planificación lingüística, con un claro mensaje político de reivindicación, la transmisión intergeneracional de las lenguas minorizadas, su uso en espacios familiares y comunitarios, allí donde era plenamente funcional ha ido disminuyendo.

Tampoco se han fortalecido los ámbitos formales propios comunales como asambleas, ritos de curación, prácticas religiosas relacionadas con la agricultura y la reproducción cultural. No es evidente que la escuela sea el lugar más idóneo para valorizar las lenguas indígenas y avanzar en su normalización dada su larga historia de negación, discriminación y rechazo de las lenguas indígenas. Quizás no podamos apostar a que modernizando las lenguas indígenas, dotándolas de normatividad, expandiendo el vocabulario, los estilos, volviéndolas lenguas escritas contribuyamos a su mantenimiento y vitalidad.

Probablemente habremos avanzado en "demostrar" a sectores o individuos de la sociedad hegemónica monolingüe en la lengua oficial de que las lenguas indígenas son complejas y "tienen gramática" cuando auspiciamos y difundimos a nivel nacional coloridas y muy bien hechas publicaciones en dichas lenguas. Zimmermann (1997: 47) reconoce que una de las razones para sostener la obligatoriedad (énfasis nuestro) de la modernización de las lenguas amerindias, su adaptación a las necesidades de comunicación actuales y futuras, es "para evitar los argumentos de los enemigos de la educación bilingüe, de que las lenguas indígenas no son aptas para la comunicación moderna, es decir, por razones de argumentación política". Habremos avanzado en la interculturalización de la sociedad hegemó- 
nica, lo cual es sin duda alguna un inmenso paso. Pero, ¿se ganan más hablantes por esta vía? ¿Se asegura la funcionalidad de las lenguas entre los hablantes? ¿Nutrimos la lealtad lingüística? ¿Propiciamos la mantención de los últimos nichos de reproducción y uso de lenguas indígenas allí donde estas tienen sus raíces y son utilizadas por defecto? Nos preguntamos con López (2003:101) "si no debiésemos abordar el tema de la planificación y la política lingüística desde una perspectiva de complementariedad entre lenguas, de juego entre lenguas, de dominios diferenciados de una lengua". Quizás es tiempo de revisar nuestra convicción de que solamente duplicando funciones para las lenguas hegemónica, y minorizada, habremos aportado a la recuperación de las lenguas indígenas.

Cuando un padre de familia cuestiona la EIB aduciendo que no tiene sentido que su hijo aprenda a escribir aimara puesto que no hay libros en aimara, está transfiriendo a "otros" (ministerio, estado) no solamente la responsabilidad sobre la educación de la siguiente generación sino también sobre el desarrollo de la lengua. $Y$ si bien en algunos países de Latinoamérica la EIB es política de Estado, tenemos suficientes demostraciones de la fragilidad de esta política más allá del discurso de moda auspiciado en el plano internacional y la falta de convicción al respecto de parte de los agentes estatales. Se sostiene que la codificación y modernización lexical son tareas prioritarias para "hacer viable una verdadera educación bilingüe e intercultural que pueda contribuir a los objetivos de revitalización de la lengua y de revalorización de su cultura" (Mendoza 1990:iv, énfasis nuestro). Concluida en algún momento la etapa de la EIB en las reformas estatales ¿habremos "empoderado" la lengua y sus hablantes? La conciencia lingüística que se despierta en el proceso de lecto-escritura no ha tenido eco en la toma de posición de los hablantes respecto a los espacios, discursos, las funciones que se requiere expandir y ampliar fuera de la escuela. 


\section{Repensando la planificación lingüística}

Enfocaremos nuestra reflexión final desde tres perspectivas relacionadas entre sí. La primera cuestiona la Reforma Educativa como instrumento de política lingüística. La segunda indaga en una distinta esfera de acción de política y planificación lingüística. Por último, establecemos requerimientos y desafíos académicos para esa distinta esfera de acción.

Coincidimos plenamente con García Castaños y otros (1999b) cuando sostienen que determinar culturas deficitarias frente a culturas no deficitarias es una práctica de desigualdad, no de diferencia. La particular manera de adaptación de los pueblos a contextos diferentes hacen justamente la diferencia entre los pueblos. Sobre esta diferencia debe fundarse la interculturalidad en general y la educación intercultural bilingüe, en especial, no sobre la desigualdad.

Reconocer el déficit de una cultura minoritaria frente a otra presuntamente mayoritaria por dominante, equivale a no admitir la capacidad de cualquier cultura para generar nuevas estrategias adaptativas en nuevos contextos y con ello negar el plano de igualdad en el que se encuentran todas las culturas y los grupos humanos que las han creado (García Castaños y otros 1999b:205).

Cabe presumir que el enfoque subyacente a la Reforma es el de asimilación. García Castaño y otros (1999a:50-51) caracterizan este enfoque con la pretensión de igualar las oportunidades educativas para alumnos culturalmente diferentes, lo cual se traduce en la intención de suplantar las diferencias por formas culturales dominantes. La base de este enfoque surge por la sustitución del término "deficiencia" por "diferencia", manteniéndose la convicción de que la pobreza se explica por el hecho de que los 
grupos culturales distintos no cuentan con las mismas oportunidades para adquirir el conocimiento y las destrezas necesarias. El objetivo de la educación será lograr la compatibilidad entre la dinámica del aula y la dinámica cultural de origen de los grupos de individuos "diferentes" al grupo cultural dominante/mayoritario que sirve como referencia en la escuela. En definitiva, se trata de diseñar sistemas de compensación educativa mediante los cuales el "diferente" pueda lograr acceder con cierta rapidez a la competencia en la cultura dominante, siendo la escuela la que facilita el "tránsito" de una cultura a la otra (íbid).

El enfoque adecuado a una posición como la esbozada por Walter Gutiérrez respecto al efecto liberador de la EIB es el de Educación como transformación (García Castaño y otros 1999a:59-60), basado en la teoría del conflicto y la teoría de la resistencia. Según estos planteamientos, los grupos oprimidos (en nuestro caso, pueblos indígenas) no se acomodan pasivamente a la situación de control que ejercen los grupos dominantes estructurando instituciones sociales para mantener o incrementar dicho control. Lo que hacen los grupos oprimidos, en este caso, los pueblos originarios, es más bien oponerse y luchar por el control de los recursos de poder, riqueza y prestigio que existen en la sociedad. En este caso, el camino hacia una educación intercultural bilingüe pasa por superar su estrechez y por su ubicación en el ámbito de las comunidades indígenas, aceptando las distintas "educaciones" que en ellas existen.

La segunda perspectiva tiene que ver con la misión de la política lingüística y su esfera de acción. Si se trata de emprender esfuerzos deliberados por influir en el comportamiento lingüístico de las personas, la planificación tendría que partir del hecho de que los individuos aprenden la lengua materna o primera en los dominios intrafamiliares e intracomunitarios. Fishman (1996:6) nos recuerda que: 
Las lenguas maternas son autosostenibles y una nueva generación no espera ir a la escuela para conseguir su lengua materna. La consigue generalmente en la casa, en la comunidad, en la vecindad entre las cosas queridas que forman la identidad del niño.

Para ser competitiva en sus propios ámbitos culturales, para infundirle a la lengua "autosostenibilidad", la planificación debe apuntar a los espacios intrafamiliares y los espacios intracomunitarios, allí donde se genera la lengua sobre una base intergeneracional (op.cit:9). Dado que no se trata de un espacio institucional como la escuela, será muchísima más ardua la tarea tanto de convocatoria como de intervención, necesitará de convicción, sustento y aporte de los mismos hablantes y de los intelectuales y profesionales indígenas en tanto mediadores ("brokers") lingüísticos.

El actual reconocimiento de lo indígena favorece una posición más contestataria que permitiría a los propios concernidos revalorizar espacios coloquiales, familiares, básicos para la reproducción humana y cultural y, por supuesto, espacios formales y rituales propios indígenas. Janks e Ivenic (1992:318) se refieren a este momento en la toma de conciencia lingüística crítica: "When the socio-historical conditions are stacked more in their favour, people may sometimes feel confident and safe enough to challenge the conventions"4.

Ahora que se escuchan discursos en lengua indígena en la academia sin recurrir después del saludo a una traducción (sucedido dos veces en el mes de noviembre de 2003 en la Universidad Mayor de San Simón en Cochabamba), ahora que la condición de indígena o de hablante

\footnotetext{
4 “Cuando las condiciones sociohistóricas están más a su favor, la gente puede a veces sentirse suficientemente confiada y segura como para desafiar las convenciones" (traducción de la autora).
} 
de una lengua indígena significa beneficios laborales y llega a ser un capital cultural, las dirigencias y los intelectuales indígenas tienen que entender que los logros políticos adquiridos solo serán conducentes a un fortalecimiento de los pueblos a los que representan si el compromiso por la resistencia a la corriente hegemónica de abandonar lo propio es asumido por las bases, los comunarios, los migrantes, hombres y mujeres. Los espacios conquistados al Estado como ser la educación formal no pueden ser más que un aliento para potenciar la reproducción cultural y lingüística en manos de cada una de las familias indígenas, de cada adulto, de cada niño y niña. Siguiendo a Abadio Green (1996) no basta la ampliación de los usos y funciones de la lengua, debe generarse una política integral propia que movilice todos los aspectos de la vida humana y social (identitarios, comunicacionales, productivos, creativos, religiosos, educativos) al interior de los grupos humanos minoritarios.

Hay un poco difundido, quizás hasta olvidado, alegato de Richard E. Littlebear (1996), indígena cheyén norteamericano, doctor en lingüística, que en términos muy explícitos nos "pone en vereda" desde la posición de quien comúnmente no ha sido llamado a planificar su lengua. Él habla sobre la situación de las lenguas nativas norteamericanas y su condición de lenguas minorizadas por el inglés, pero ustedes verán cuán pertinente resulta para Latinoamérica y sus lenguas:

Desde tiempos inmemoriales, nuestros idiomas nativos americanos han sido orales. Algunos de ellos se han estado escribiendo solamente en los últimos tres siglos. Debemos recordar esta tradición oral a la hora de enseñar nuestros idiomas.

A veces negamos esta tradición oral al seguir ciegamente el único modelo de enseñanza de un idioma que conocemos: la forma en la que se nos enseñó el idioma 
inglés, poniendo un gran énfasis en la gramática. Enseñar nuestros idiomas como si no tuvieran una tradición oral es un factor que contribuye al fracaso de los programas de enseñanza de idiomas nativos americanos, de tal modo que ahora tenemos algo así como una tradición del fracaso.

Probablemente debido a esta tradición del fracaso, nos adherimos a cualquier cosa que parezca que puede preservar nuestros idiomas. Como resultado, ahora tenemos una letanía sobre lo que considerábamos era el único modo de salvar nuestras lenguas. Esa única manera era muy rápidamente reemplazada por otra.

Por ejemplo, algunos de nosotros decíamos, "Pongamos nuestros idiomas por escrito" y lo hicimos, y aun así nuestras lenguas nativas seguían muriéndose".

Luego dijimos, "Hagamos diccionarios para nuestros idiomas" y lo hicimos, y aun así las lenguas seguían muriéndose.

Luego dijimos, "Formemos lingüistas entrenados en nuestras lenguas" y lo hicimos, y aun así nuestras lenguas nativas seguían muriéndose.

Luego dijimos, "Preparemos a nuestra propia gente que habla nuestros idiomas como lingüistas" y lo hicimos, y aun así nuestras lenguas nativas seguían muriéndose.

Luego dijimos, "Solicitemos una asignación de fondos federales para la educación bilingüe" y lo hicimos, y aun así nuestras lenguas nativas seguían muriéndose.

Luego dijimos, "Dejemos que en las escuelas se enseñen nuestras lenguas" y lo hicimos, y aun así nuestras lenguas nativas seguían muriéndose.

Luego dijimos, "Desarrollemos materiales culturalmente relevantes" y lo hicimos, y aun así nuestras lenguas nativas seguían muriéndose.

Luego dijimos, "Recurramos a muy buenos hablantes para que enseñen nuestras lenguas" y lo hicimos, y aun así nuestras lenguas nativas seguían muriéndose. 
Luego dijimos, "Grabemos a los mayores hablando nuestros idiomas" y lo hicimos, y aun así nuestras lenguas nativas seguían muriéndose.

Luego dijimos, "Filmemos a los mayores hablando nuestros idiomas y realizando actividades culturales" y lo hicimos, y aun así nuestras lenguas nativas seguían muriéndose.

Luego dijimos, "Grabemos a nuestros hablantes nativos en CD-ROM" y lo hicimos, y aun así nuestras lenguas nativas seguían muriéndose.

Finalmente, alguien dirá, "Hagamos congelar a los pocos hablantes que nos quedan, de manera tal que cuando la tecnología avance, ellos puedan ser revividos y así contaremos con nuevos hablantes de las lenguas nativas norteamericanas," y lo haremos y estos sujetos resucitados despertarán en un distante mundo del futuro cuando ellos sean los únicos hablantes de sus idiomas porque entonces todos los otros hablantes de esos mismos idiomas habrán desaparecido y nadie los entenderá. En esta letanía, hemos visto en cada recurso la salvación de nuestros idiomas - y no lo han sido.

Por supuesto que apelar a la tecnología criogénica y al congelamiento instantáneo son medidas desesperadas. El punto es que, a pesar de los avances en los métodos de enseñanza y en la tecnología y nuestra creciente dependencia de ellos, nuestros idiomas siguen muriéndose. En este proceso de muerte también juega un rol el constante agotamiento de quienes hablan lenguas nativas. Nuestros idiomas tienen pocos medios, como el nacimiento, de reaprovisionarse de hablantes nativos, y aun el nacimiento está fallando porque no estamos enseñando a nuestros recién nacidos a hablar sus idiomas nativos.

Otros idiomas americanos se perpetúan con el influjo periódico de inmigrantes hacia los Estados Unidos. 
Nuestras lenguas no se pueden dar el lujo de este influjo porque en ninguna parte de este mundo, por ejemplo, se habla el Athabascan Gwich'in. Esta falta de influjo pone a nuestros idiomas en una posición única pero muy vulnerable. Son únicos porque representan un microcosmos completo con su propia lingüística, perspectiva del mundo, espiritualidad, carácter y comunidad de parlantes. Son vulnerables porque existen en el macrocosmos del idioma inglés y su impresionante capacidad de desplazar y eliminar a otras lenguas.

Para revertir esta influencia del inglés, las familias deben rescatar su legítima posición de ser las primeras maestras de nuestros idiomas. Ellas deben hablar nuestros idiomas cada día, en todo lugar, con todos, en cualquier lugar. Pero si van a relegar a las escuelas su responsabilidad de enseñar, entonces deben apoyarlas. Deben asegurarse de que las escuelas usen métodos de enseñanza basados en el lenguaje oral (énfasis nuestro). Debemos usar todos los recursos (excepto la congelación instantánea) de la letanía por preservar nuestros idiomas en lugar de cifrar todas nuestras esperanzas solo en uno.

Eso significa que debemos saber cuál es el recurso apropiado. Saber cuál es el lugar apropiado con frecuencia depende de saber cuánta pérdida ha habido en el grupo que habla ese idioma. Por ejemplo, un idioma que sólo hablan personas mayores de 60 años puede no ser ya viable para un programa de inmersión en esa lengua. La razón es que para enseñar el idioma se requiere demasiada energía para un grupo de esa edad.

Este ejemplo anterior nos muestra por qué debemos debatir los temas que rodean a los esfuerzos por preservar los idiomas nativos americanos y los idiomas nativos de Alaska. Estos temas están cambiando constantemente y debemos estar al corriente para poder mantener un gran nivel de esfuerzo en preservar la lengua. 
Debemos superar la etapa de autovictimización y dejar de señalar a la Oficina de Asuntos Indígenas, las escuelas misioneras, los medios de comunicación y las escuelas públicas como las causas de que nuestros idiomas se estén perdiendo. Aunque estamos en lo cierto cuando les culpamos por la pérdida de nuestros idiomas, queda el simple y puro hecho de que estas entidades no nos van a ayudar a restaurar, revivir o preservar nuestros idiomas. No tienen interés alguno en estos esfuerzos por preservar nuestras lenguas. De hecho, están por tener éxito en lograr aquello para lo que sí tienen interés: matar nuestros idiomas.

Es así que la responsabilidad por salvar nuestros idiomas es nuestra y solo nuestra; somos la generación fundamental porque probablemente seamos la última generación de hablantes que puede hacer bromas, conversar sobre temas netamente técnicos, articular un dolor psíquico profundo y también discutir estrategias apropiadas para sanarlo sin recurrir una sola vez al idioma inglés.

Conclusión

Nuestras lenguas nativas americanas están en el momento penúltimo de su existencia en este mundo. Es la única y última vez que tendremos la oportunidad de salvarlas. Debemos continuar promoviendo a través de Alaska y el país de los Indígenas aquellos programas que han tenido éxito.

Debemos dejar de estar eternamente lamentándonos y continuamente catalogando las causas de que muera un idioma; en lugar de ello, debemos ahora lidiar con estos temas, aprendiendo de los esfuerzos que han tenido éxito en preservar idiomas.

Así que si no hacemos nada, entonces podemos contar conque nuestras lenguas hayan muerto para fin de siglo. Aun ese margen podría ser optimista si no hacemos nada por preservar nuestros idiomas. 
Se abrirá un gran vacío en el universo que nunca podrá llenarse cuando todas nuestras lenguas mueran.

Littlebear apuesta al uso de la lengua por sobre todo, en todo lugar y en todo tiempo, incluyendo a la escuela, siempre y cuando sea decisión de los hablantes y la enseñanza propiciada en ella respete la oralidad de la lengua. Su alegato apunta a una complementariedad de estrategias (López 1996:380) como expresión de militancia lingüística asumida por propia convicción y así cortar con la actitud de victimización, resignación y fatalismo de los hablantes de lenguas minorizadas.

En cuanto a argumentos desde la posición teórica, podemos recurrir a Ricento (2000: 16-23), quien se refiere a una nueva etapa de la planificación lingüística en la época del reconocimiento de los derechos lingüísticos dentro de una concepción ecológica de las lenguas: "It seems that the key variable which separates the older, positivist technicist approaches from the newer critical/postmodern ones is agency, i.e. the role(s) of individuals and collectivities in the processes of language use, attitudes, and ultimately policies" ${ }^{5}$ (íbid). En el centro de atención de este paradigma sociolingüístico no está la lengua como tal sino el comportamiento lingüístico y la identidad de los hablantes (íbid).

La tercera perspectiva se refiere a las herramientas académicas o conceptuales útiles para la aplicación de esta política lingüística, es decir, para la respectiva planificación. En este cometido, creemos que nos ayuda la reflexión sobre los diferentes discursos que se tejen en torno a la oralidad y la escritura como reivindicación del discurso oral y de la oralidad. Siguiendo la reflexión de Garcés (2005) sobre Marcone (1997), tras las buenas intenciones de reivindicar

\footnotetext{
5 "Parece que la variable clave que separa los enfoques más antiguos positivistas/tecnicistas de los más nuevos críticos/postmodernos es agencia, es decir, el o los roles de individuos y colectividades en los procesos de uso de lenguas, actitudes y, en última instancia, políticas" (traducción de la autora).
} 
la oralidad; en el fondo lo que realmente se hace es atraparla en las mismas categorías del mundo de la escritura que se critica. Vigil (2004) demuestra con ejemplos de textos producidos por una institución capacitadora en EBI en la zona de Urubamba, Cuzco, Perú, la práctica de traducción de contenidos y géneros de la cultura hegemónica en programas de lectura y escritura en lenguas indígenas, llegando a la conclusión que "Se desconoce cómo las distintas culturas organizan sus discursos y se piensa que la manera de organizarlos en castellano es la única existente" (op.cit:193). Los intentos de plasmar la oralidad en los textos literarios y escritos son una "ilusión de la oralidad" puesto que se trabaja a partir de esquemas y nociones propias de la escrituralidad. Hablando del "descubrimiento moderno y postmoderno de la oralidad” (op.cit.:33), para Marcone (íbid), la contradicción fundamental de los estudios contemporáneos sobre oralidad es que la noción de "oralidad" es una construcción discursiva de aquella subjetividad que los mismos estudios sobre oralidad asocian con la escritura alfabética o, mejor aún, con la cultura del libro. De hecho, la "oralidad" es una categoría en la que la escritura se recrea o en la que proyecta aquello que entiende como sus carencias.

Se precisan relecturas del discurso oral y la búsqueda de escrituras alternativas a partir de la revisión crítica de las aproximaciones que desde la academia y las disciplinas como la pedagogía, la lingüística, la literatura, hasta la antropología, se hizo hacia las lenguas indígenas. Una renovada mirada a la cotidianeidad como lugar de reproducción cultural por excelencia debe provocarnos también mayor apertura hacia y reconocimiento de las diversas educaciones, hablas, fijaciones verbales. Esta tarea está relacionada con los niveles y espacios de intervención, de planificación lingüística implícitos en la primera reflexión. Cantoni (1997:6) nos alerta: 
To keep languages alive, it is not enough to value them; it is essential to use them. If their use is declining, it is necessary to identify special occasions and designate special times and places where it makes sense not to use [Spanish]. The community must provide direction. ${ }^{6}$

Aun esfuerzos por recuperar el uso de la lengua ante la norma como se hizo, por ejemplo, para el caso del euzkera, también terminaron favoreciendo los espacios formales como la escuela y, por lo tanto, respondieron a sus fines de crear y potenciar el instrumento que en el mundo entero define el rol de la escuela: la adquisición y transmisión de la escritura. En el país vasco, justamente, con los ejemplares avances y logros en la planificación lingüística, el gobierno propicia el uso del euskera en espacios familiares y de ocio otorgando vacaciones pagas con la condición de que en ellas se utilice la lengua (L. E. López, comunicación personal). La ilusión de la oralidad es superada solamente en la medida en que la oralidad se torna en nuestro medio y fin de estudio e intervención. Hay indicios de que este no es un camino fácil y gratificante. Sin embargo, en Latinoamérica estos criterios no han sido necesariamente tenidos en cuenta a la hora de actuar.

\footnotetext{
6 "Para mantener vivas las lenguas, no es suficiente valorarlas; es esencial usarlas. Si su uso está declinando, es necesario identificar ocasiones especiales y designar tiempos y espacios especiales en los cuales hace sentido no usar [castellano]. La comunidad debe dar dirección" (Traducción de la autora)
} 
